\title{
Hypolipidaemic effect of chemically different mucilages in rats: a comparative study
}

\author{
Puthenpura T. Boban ${ }^{1}$, Bala Nambisan ${ }^{2}$ and Perumana R. Sudhakaran ${ }^{1} *$ \\ ${ }^{1}$ Department of Biochemistry, University of Kerala, Kariavattom Campus, Thiruvananthapuram, Kerala 695 581, India \\ ${ }^{2}$ Central Tuber Crops Research Institute, Thiruvananthapuram, Kerala, India
}

(Received 30 January 2006 - Revised 3 July 2006 - Accepted 24 July 2006)

\begin{abstract}
Different classes of fibres differ in their potential to lower lipid levels. In order to examine how chemically diverse fibres differ in their hypolipidaemic activity, mucilages of varying chemical composition isolated from three different sources were administered to experimental animals and the metabolism of lipids and lipoproteins was studied. The mucilages used were a galactomannan isolated from fenugreek (Trigonella foenumgraecum) seeds, a glucomannan from Dioscorea esculenta tubers and an arabinogalactan from Colocasia esculenta tubers. Rats were fed these mucilages at a dose of $4 \mathrm{mg} / 100 \mathrm{~g}$ body weight per $\mathrm{d}$ for 8 weeks and the changes in the levels of total cholesterol and triacylglycerols in serum, liver and aorta were analysed. All these mucilages decreased lipid levels both in serum and tissues. Among these mucilages, glucomannan showed the most hypolipidaemic effect followed by galactomannan and arabinogalactan. Further, hepatocytes were isolated from the livers of mucilage-fed rats and the synthesis and secretion of lipoproteins were studied using metabolic labelling. There was a decrease in the synthesis and secretion of apoB-containing lipoproteins, mainly VLDL, by hepatocytes isolated from mucilage-fed rats when compared to control $(P<0.05)$. This was further confirmed by pulse chase analysis. Among the different mucilages, mannose-rich glucomannan showed the most effect followed by galactomannan, and mannose-free arabinogalactan showed minimal effect. Comparison of relative viscosity and water-holding capacity showed that mannan-rich mucilages like galactomannan and glucomannan, which showed greater hypolipidaemic effect, had greater relative viscosity and water-holding capacity. The present results suggested that the hypolipidaemic effect of dietary fibre involves a decrease in hepatic production of VLDL and further that it varies with the nature of the fibre.
\end{abstract}

Rat hepatocytes: VLDL: Dietary fibre: Mucilage

Dietary fibres are important constituents of diet which have been reported to have remarkable beneficial effects that include their hypolipidaemic property (Anderson, 1985). These substances of plant origin include a number of NSP materials like cellulose, hemicellulose, $\beta$-glucans, pectins, mucilages and gums and the non-polysaccharide lignin. These fibres have unique chemical structures and characteristic physical properties (Kay, 1982; Van Horn, 1997; Anderson \& Hanna, 1999). The physical characteristics of dietary fibres include high water-holding capacity, viscosity, fermentability and adsorption/binding to different biomolecules and metallic ions (Schneeman \& Tietyen, 1994). Fibres with high water-holding capacity, such as pectin, gums and mucilages, have been referred to as soluble fibre.

Different classes of fibres differ in their potential to lower lipid levels (Kritchevsky \& Stony, 1986; Anderson et al. 1994). Certain fibres, particularly soluble fibres capable of forming gels, appear to be effective in lowering serum levels of total and LDL cholesterol in normal subjects as well as in those with hyperlipidaemia. Specific mechanisms involved in the hypolipidaemic effect of dietary fibre remain inconclusive. Recent research provides evidence that the hypocholesterolaemic effect of dietary fibre may be due to fibre-induced alterations of intestinal absorption, intestinal or pancreatic hormone secretion, lipoprotein metabolism, bile acid metabolism, or by-products of fermentation and their effect on hepatic cholesterol synthesis. Gallaher et al. (1993) and Carr et al. (1996) showed that the viscosity of dietary fibre is related to its cholesterol-lowering effect in hamsters fed a cholesterol-supplemented diet. Fermentation of fibre can lead to an enhanced production of SCFA, particularly propionate, which may be involved in the hypocholesterolaemic effect of certain soluble plant fibres (Chen et al. 1984). SCFA produced by caecal fermentation of dietary fibre have been reported to suppress cholesterol synthesis in rat liver and intestine (Hara et al. 1999). Within the same class of dietary fibre, there are differences in physiological activity, which may be attributed, at least partially, to differences in chemical nature (Evans et al. 1992); but this aspect has not been investigated in detail.

Mucilages are synthesized by plant secretory cells and help prevent desiccation of seed endosperm. Mucilaginous fibres such as pectin, guar and psyllium seed colloid have consistently been shown to increase bile acid excretion (Kay, 1982). In order to study how the serum lipid-lowering effect of the dietary fibre is related to its chemical nature, mucilages

Abbreviations: GOT, glutamate oxaloacetate transaminase; GPT, glutamate pyruvate transaminase.

* Corresponding author: Dr Perumana R. Sudhakaran, fax +91 471 2418078, email prsbn@md4.vsnl.net.in 
having different chemical natures were assessed for their hypolipidaemic effect. Relative hypolipidaemic effect and the mechanism of action of a glucomannan, a galactomannan and an arabinogalactan, mucilages of different chemical nature isolated from three different sources, were investigated and the results are presented here.

\section{Materials and methods}

\section{Chemicals}

Eagles minimum essential medium, type IV collagenase, penicillin, streptomycin and protein-A-sepharose were purchased from Sigma (St Louis, MO, USA). $\left[{ }^{14} \mathrm{C}\right]$ Leucine (uniformly labelled with high specific activity), $\left[{ }^{14} \mathrm{C}\right]$ acetate (specific activity $1.5466 \mathrm{GBq} / \mathrm{mmol}$ ) and $\left[{ }^{35} \mathrm{~S}\right]$ methionine (specific activity $37.0 \mathrm{TBq} / \mathrm{mmol}$ ) were purchased from BRIT (Mumbai, India). Plastic tissue culture dishes were purchased from NUNC (Denmark). Anti-rat apoB antisera in rabbit, prepared in our laboratory as described earlier, was used (Anil et al. 1992). All other chemicals used were of high purity analytical grade.

\section{Preparation of mucilages}

Fenugreek (Trigonella foenum-graecum) seeds were washed with water, dried and finely powdered. The powder was extracted with $95 \%$ ethanol, until it became colourless. The dry defatted powder was then extracted with distilled water at $4^{\circ} \mathrm{C}$. It was centrifuged and cold TCA was added to a final concentration of $5 \%$, mucilage was precipitated from the supernatant by the addition of three volumes of $95 \%$ ethanol. This was then washed with $95 \%$ ethanol, dissolved in water, dialysed against water, and the mucilage was reprecipitated with three volumes of ethanol, then dried and powdered. To isolate mucilages from Colocasia esculenta and Dioscorea esculenta, $25 \mathrm{~g}$ tuber flour was extracted with cold $10 \%$ TCA, centrifuged and to the supernatant four volumes of acetone was added, the precipitated mucilage was collected by centrifugation at $10000 \mathrm{rpm}$, dissolved in water, dialysed against water and reprecipitated with four volumes of acetone. The mucilages were dried and powdered.

\section{Characterization of mucilages}

The yield of mucilage was determined as the weight of dry mucilage powder obtained. The purity of the mucilage was assessed by analysing carbohydrate by the phenol sulphuric acid method (Kochert, 1978) and testing protein by the method of Lowry et al. (1951).

For chemical analysis, an aqueous solution of mucilage was hydrolysed by heating with $1 \mathrm{M}-\mathrm{H}_{2} \mathrm{SO}_{4}$ in a sealed tube under $\mathrm{N}_{2}$ atmosphere in a boiling water-bath for 4-6h. The solution was neutralized with barium carbonate, centrifuged and the supernatant was filtered through $0.2 \mu \mathrm{m}$ filter and used for determination of monosaccharide components both by descending paper chromatography (butanol-acetic acid-water, 4:1:5, by vol.) and HPLC. HPLC was carried out using a Shimadzu HPLC system (Shimadzu, Kyoto, Japan) with acetonitrile-water $(80: 20, \mathrm{v} / \mathrm{v})$ as mobile phase using a Supelco-LC-NH 2 column and a RI detector. The $R_{\mathrm{t}}$ values were compared with those of standard sugars, the peak areas were noted and the relative content of sugars calculated.

\section{Measurement of viscosity}

Relative viscosities of mucilage solutions were measured using an Ostwald's viscometer held in a temperature-controlled water-bath. Time of flow was measured in triplicate, the average values taken and the relative viscosity calculated.

\section{Determination of water-holding capacity}

For the determination of the water-holding capacity of mucilages the modified method of McConnell (McConnell et al. 1974) was employed. Sample (0.5 g) was transferred to a preweighed $50 \mathrm{ml}$ polypropylene centrifuge tube with screw cap. To each tube, $30 \mathrm{ml}$ distilled water were added, the tube was placed in a forced-air oven at $37^{\circ} \mathrm{C}$ with moderate shaking for $16 \mathrm{~h}$. The tubes were then centrifuged at $2000 \mathrm{~g}$ for $15 \mathrm{~min}$ and excess water was decanted. Each tube was weighed. The amount of water held was calculated by subtracting the weight before and after water treatment and was expressed on a dry weight basis.

\section{Animals and diet}

Twenty-four male albino rats (Sprague-Dawley strain, weighing $100-120 \mathrm{~g}$ ) were randomly divided into four groups of six rats each. Animals were housed in plastic cages individually in a temperature- and light-controlled room and fed ad libitum on standard laboratory feed (approximate composition: protein, $221 \mathrm{~g} / \mathrm{kg}$; fat, $40 \mathrm{~g} / \mathrm{kg}$; fibre, $36 \mathrm{~g} / \mathrm{kg}$; minerals, $50 \mathrm{~g} / \mathrm{kg}$; energy, $15 \cdot 16 \mathrm{~kJ} / \mathrm{g}$ ) and water. For oral administration, the required amount of mucilage was suspended in water and shaken on a rocker for about an hour until it dissolved to form a homogeneous solution. Aqueous solutions $(2 \mathrm{ml})$ of galactomannan, arabinogalactan and glucomannan, isolated from fenugreek seeds, Colocasia and Dioscorea tubers, respectively, were administered orally by intubation at a dose of $4 \mathrm{mg} / 100 \mathrm{~g}$ body weight per $\mathrm{d}$ to one group each and the fourth group of animals maintained under identical conditions receiving $2 \mathrm{ml}$ distilled water/d, served as control. The mucilage solution was administered immediately before feeding. The experiments were carried out with the approval of the Institutional Animal Ethics Committee. The duration of the experiment was 8 weeks. Body weights were recorded weekly during the experimental period.

\section{Sampling procedures}

During the last $2 \mathrm{~d}$ of the experimental period, faecal samples were collected from each rat and stored at $-20^{\circ} \mathrm{C}$. At the end of the experimental period, rats were deprived of food for $16 \mathrm{~h}$ and then anaesthetized with ether inhalation and killed by decapitation. Blood samples were collected into tubes without an anticoagulant, kept at room temperature for $1 \mathrm{~h}$, and serum was separated by centrifugation at $4^{\circ} \mathrm{C}$ for $20 \mathrm{~min}$ at $1500 \mathrm{~g}$. Serum was stored at $-20^{\circ} \mathrm{C}$ until analysed. Livers were perfused with cold PBS to remove blood and individual livers were taken, sliced and portions equivalent to about $500 \mathrm{mg}$ were taken for analysis. Adventitial fat was removed from 
aorta, washed in cold PBS and whole aorta was used for extraction and analysis of lipids. Tissues from each animal were analysed separately.

\section{Analytical procedures}

Serum total cholesterol was determined by the cholesterol oxidase method (Zlatkis et al. 1953). Triacylglycerols in the serum were estimated by the glycerol phosphate oxidase method (Fossati \& Prencipe, 1982). Serum glutamate oxaloacetate transaminase (GOT) and glutamate pyruvate transaminase (GPT) were estimated by the method of Reitman \& Frankels (1957). Total protein and albumin to globulin ratio was determined by the Biuret method. These estimations were done with commercially available reagent kits (Qualigen's Diagnostics, Mumbai, India). Serum VLDL + LDL was precipitated using heparin $-\mathrm{MnCl}_{2}$ solution (Gidez et al. 1982) and the lipids in the VLDL + LDL fraction were extracted (Folch et al. 1957) and cholesterol estimated (Carr \& Drektor, 1956). ApoB in the VLDL + LDL fraction was precipitated using heparin- $\mathrm{MnCl}_{2}$ (Gidez et al. 1982), subjected to SDS-PAGE using 5-15\% gradient gel (Laemmli, 1970), stained with Coomassie Brilliant Blue R-250 and the intensity of bands was measured using the Quantity One program in a BioRad gel doc. Lipids were extracted from tissues (Folch et al. 1957) and estimated for cholesterol (Carr \& Drektor, 1956) and triacylglycerols (Van Handel \& Zilversmith, 1957). Faecal samples from rats of all groups were homogenized with an equal volume of water and lyophilized to a fine powder. From this powder faecal neutral sterols and bile acids were extracted (Grundy et al. 1965) and estimated as described earlier (Menon \& Kurup, 1976).

\section{Isolation and culture of hepatocytes}

Hepatocytes were isolated from rats of all four groups, which were starved overnight, by collagenase perfusion (Seglen, 1976) as described earlier (Sudhakaran et al. 1980). The isolated hepatocytes were examined by light microscopy and the viability was tested by the ability of cells to exclude $0.5 \%$ trypan blue. Cell preparations with more than $90 \%$ viability were used for experiments and they retained their viability in culture during the experimental period. Hepatocytes in minimum essential medium (approximately $2.5 \times 10^{6}$ cells/ $\mathrm{ml}$ ) were seeded on $35 \mathrm{~mm}$ plastic culture dishes. After $4 \mathrm{~h}$, unattached cells were removed and the monolayers of attached cells were used for the study.

\section{Metabolic labelling of hepatocytes}

The cells in culture were metabolically labelled by incubating with serum-free leucine-deficient medium containing $\left[{ }^{14} \mathrm{C}\right] l$ leucine $(185 \mathrm{kBq} / \mathrm{ml})$. The cells were also incubated separately with serum-free medium containing $\left[{ }^{14} \mathrm{C}\right]$ acetate $(185 \mathrm{kBq} /$ $\mathrm{ml}$ ). Cells were maintained at $37^{\circ} \mathrm{C}$ in a $95 \%$ air and $5 \%$ $\mathrm{CO}_{2}$ atmosphere for different time intervals. At the end of the incubation period, the medium and cells were collected separately for analysis.

\section{Pulse chase experiment}

The attached monolayer of hepatocytes were pulse labelled with $\left[{ }^{35} \mathrm{~S}\right]$ methionine $(740 \mathrm{kBq} / \mathrm{ml})$ for $3 \mathrm{~h}$. After removing the radioactive medium, the cells were maintained in nonradioactive medium. The radioactivity associated with apoB that secreted into the medium was chased at different time intervals ( 2 and $4 \mathrm{~h})$.

\section{Immunoprecipitation of cellular and secreted apoB}

After separation of hepatocytes and media, the cell pellet was resuspended in $1 \mathrm{ml} 20 \mathrm{~mm}-\mathrm{PBS}, \mathrm{pH} \mathrm{7.4}$. Cell protein was estimated by the method of Lowry et al. (1951). The medium was centrifuged at $10000 \mathrm{~g}$ for $5 \mathrm{~min}$ to remove any cell debris. ApoB was immunoprecipitated from cells and media and the incorporation of radioactivity into apoB was determined as described previously (Anil \& Sudhakaran, 1994) using antirat apoB.

\section{TLC separation of lipids in lipoproteins}

Lipids associated with the lipoprotein that was secreted into the medium and that associated with the cell layer were extracted by the method of Folch et al. (1957). Individual lipids were separated by TLC (Skipski et al. 1968) on silica gel $G$ plates with a solvent mixture of hexane-diethyl ether-acetic acid (80:20:1, by vol.). Authentic lipid standards were run concurrently and the TLC plates were developed using iodine vapour. Individual lipids were located as spots corresponding to standards. Silica gel corresponding to different lipids were scraped, extracted with chloroform and the radioactivity associated with each lipid was measured separately by liquid scintillation counting.

\section{Statistical analysis}

All values are expressed as means and standard deviations. Data were analysed by one-way ANOVA, and significant differences among groups were determined by Duncan's multiple range test $(P<0 \cdot 05)$. The statistical analyses were done using SPSS Statistical Package for Windows version 10.0 (SPSS, Chicago, IL, USA).

\section{Results}

\section{Isolation of mucilages}

The yield of mucilages was as follows: fenugreek, $8 \mathrm{~g} / 100 \mathrm{~g}$ seeds; Colocasia, $1 \mathrm{~g} / 100 \mathrm{~g}$ dry flour; Dioscorea, $0.8 \mathrm{~g} / 100 \mathrm{~g}$ dry flour. Dry powder of fenugreek mucilage contained $92 \%$ carbohydrate and $3 \%$ protein. Dioscoria mucilage contained $89 \%$ carbohydrate and $5 \%$ protein whereas Colocasia mucilage contained $90 \%$ carbohydrate and $5 \%$ protein. No starch was detected in any of the mucilages. Acid hydrolysis followed by separation of sugars by paper chromatography and HPLC showed that fenugreek mucilage was a galactomannan containing galactose and mannose in the ratio $1: 1$, Colocasia mucilage was an arabinogalactan containing galactose and arabinose in the ratio 2:1 and Dioscorea mucilage was a glucomannan with a trace (less than $5 \%$ ) amount of glucose. 
These mucilages were resistant to degradation by salivary amylase in vitro.

\section{Animal growth}

Although animals receiving different mucilages showed some reduction in feed consumption during the early few days of the experiment, there was no statistically significant difference in body weight gain when compared to control animals and among different groups. The weight gain for control, galactomannan, arabinogalactan and glucomannan groups were 112 (SD 5), 109 (SD 5), 112 (SD 4) and 109 (SD 4) g/8 weeks, respectively.

\section{Serum glutamate oxaloacetate transaminase, glutamate pyruvate transaminase and proteins}

In order to assess hepatic function, markers of liver function such as the activities of serum GOT and GPT, and the amount of total protein and albumin/globulin ratios were determined and the results are given in Table 1. There was no significant difference in the activities of serum GOT and GPT in rats of different diet groups when compared with control rats. The amount of total protein and the albumin:globulin ratio also did not show any statistically significant difference in rats of different diet groups when compared with control.

\section{Serum lipids}

To compare the effect of different mucilages on serum lipids, serum collected from rats of all four groups were analysed for total cholesterol, HDL/VLDL + LDL cholesterol and triacylglycerols. The results are given in Table 2. There was significant reduction in total cholesterol in the serum of rats fed galactomannan and glucomannan $(P<0.05)$ compared to control rats. Arabinogalactan-fed rats showed no statistically significant change in serum total cholesterol levels. Cholesterol in the VLDL + LDL fraction of the lipoprotein decreased significantly in mucilage-fed rats when compared to control. But there was no difference in cholesterol level in these lipoproteins in any of the three different mucilage diet groups. However, serum HDL/VLDL + LDL cholesterol ratio was found to be increased significantly in rats fed galactomannan, arabinogalactan and glucomannan compared to control rats
$(P<0 \cdot 05)$. Serum triacylglycerols decreased significantly in all the mucilage groups compared to control $(P<0 \cdot 05)$. Glucomannan-fed rats showed more effect followed by arabinogalactan and galactomannan (Table 2). ApoB, the principal apoprotein in VLDL and LDL, also decreased.

\section{Tissue lipids}

Lipids were extracted from liver and aortic tissues and amounts of cholesterol and triacylglycerols were estimated and the results are shown in Table 2. Liver cholesterol and triacylglycerols were significantly reduced in all the mucilage groups compared to control $(P<0 \cdot 05)$. Aortic cholesterol decreased significantly in galactomannan- and glucomannanfed rats compared to control; a greater decrease in aortic cholesterol was observed in glucomannan-fed rats $(P<0.05)$ followed by galactomannan-fed rats $(P<0 \cdot 05)$. Aortic triacylglycerols were found to be decreased significantly in all the three mucilage groups, glucomannan-fed rats showed a greater effect followed by galactomannan and arabinogalactan, compared to control rats.

\section{Faecal bile acids and neutral sterols}

Faecal bile acid and neutral sterols were estimated and the results are given in Fig. 1. Faecal bile acid excretion increased significantly in rats of all mucilage groups, namely rats fed galactomannan $(P<0.05)$, arabinogalactan $(P<0.05)$ and glucomannan $(P<0.05)$ compared to control rats. Faecal neutral sterol excretion also increased significantly in all the diet groups; namely rats fed galactomannan $(P<0.05)$, arabinogalactan $(P<0.05)$ and glucomannan $(P<0.05)$ compared to control rats. But there was no significant difference in the amount of bile acids and neutral sterols excreted by animals among the various mucilage-fed groups.

\section{Synthesis and secretion of $a p o B$ by hepatocytes}

The synthesis and secretion of VLDL was studied using hepatocytes isolated from livers of animals fed mucilage and maintained in culture. This was studied by metabolic labelling of apoB, the major apoprotein of VLDL, and $\left[{ }^{14} \mathrm{C}\right]$ acetate into lipids. The incorporation of $\left[{ }^{14} \mathrm{C}\right]$ leucine into apoB secreted into the medium, at different time intervals, was found to be

Table 1. Serum glutamate oxaloacetate transaminase (GOT) and serum glutamate pyruvate transaminase (GPT) activities, and serum total protein concentration and albumin:globulin ratio in rats fed different mucilages*

(Mean values and standard deviations for six rats per group)

\begin{tabular}{|c|c|c|c|c|c|c|c|c|}
\hline & \multicolumn{2}{|c|}{$\begin{array}{l}\text { Serum GOT } \\
\text { (units/ml) }\end{array}$} & \multicolumn{2}{|c|}{$\begin{array}{l}\text { Serum GPT } \\
\text { (units/ml) }\end{array}$} & \multicolumn{2}{|c|}{$\begin{array}{l}\text { Total protein } \\
(\mathrm{mg} / 100 \mathrm{ml})\end{array}$} & \multicolumn{2}{|c|}{$\begin{array}{c}\text { Albumin:globu- } \\
\text { lin ratio }\end{array}$} \\
\hline & Mean & SD & Mean & SD & Mean & SD & Mean & SD \\
\hline Control & $40 \cdot 26$ & 4.02 & $30 \cdot 81$ & 3.84 & $7 \cdot 01$ & 1.05 & $1 \cdot 37$ & 0.11 \\
\hline Galactomannan & 42.92 & 3.78 & $28 \cdot 67$ & $3 \cdot 24$ & $6 \cdot 82$ & $1 \cdot 20$ & 1.42 & 0.13 \\
\hline Arabinogalactan & $39 \cdot 29$ & 3.74 & $29 \cdot 12$ & 1.95 & $7 \cdot 26$ & 1.84 & 1.35 & 0.09 \\
\hline Glucomannan & $38 \cdot 16$ & 4.57 & 32.62 & 3.71 & 6.92 & 1.43 & 1.32 & 0.11 \\
\hline
\end{tabular}

* Rats were divided into four groups and fed normal diet. Animals of three groups were fed galactomannan, arabinogalactan and glucomannan $4 \mathrm{mg} / 100 \mathrm{~g}$ body weight daily for 8 weeks and the serum was collected and analysed. For details of procedures, see p. 1023. There was no significant differences among different diet groups: $P<0.05$. 


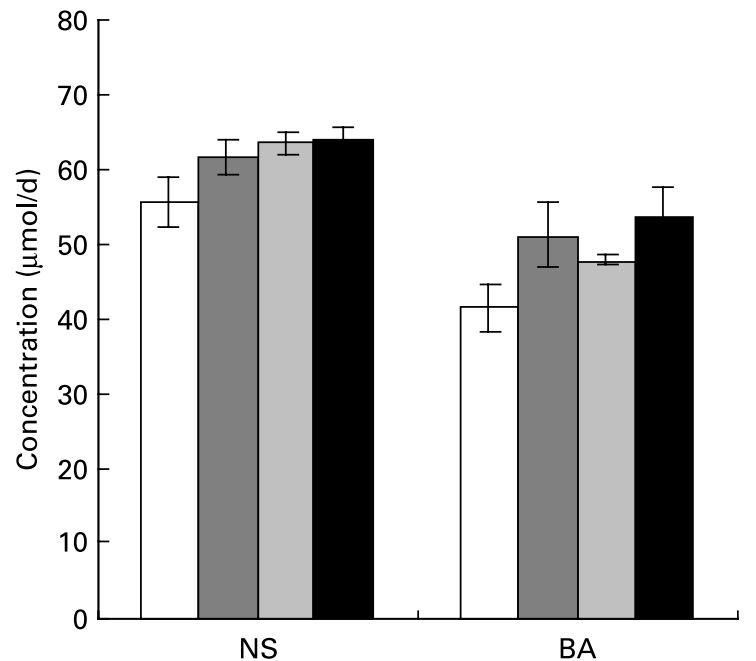

Fig. 1. Concentrations of total neutral sterols (NS) and total bile acids (BA) in faeces of rats fed different mucilages. Rats were fed control diet $(\square)$, galactomannan ( $\square$ ), arabinogalactan ( $\square$ ) or glucomannan ( $\square$ ) for 8 weeks at a concentration of $4 \mathrm{mg} / 100 \mathrm{~g}$ body weight per d. Stool samples $(24 \mathrm{~h})$ were collected and analysed for NS and BA. For details of procedures, see p. 1023. Values are means with standard deviations depicted by vertical bars ( $n$ 6). All mean values were significantly different from those of the control group: $P<0.05$. There were no significant differences among the different mucilage groups for either NS or BA.

less in cells derived from the livers of rats of mucilage diet group when compared to control rats (Fig. 2). The reduction was more in hepatocytes isolated from glucomannan-fed rats $(P<0.05)$, followed by galactomannan-fed $(P<0.05)$ and arabinogalactan-fed $(P<0 \cdot 05)$ rats. However, incorporation

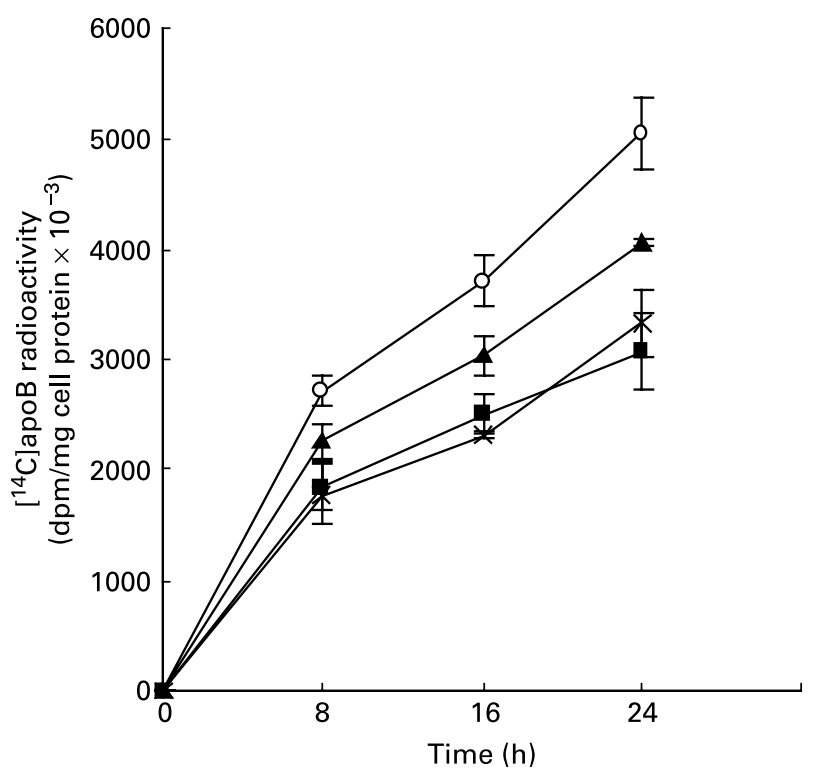

Fig. 2. Synthesis of $\left[{ }^{14} \mathrm{C}\right] \mathrm{apoB}$ by hepatocytes isolated from rats fed different mucilages. Hepatocytes isolated from livers of rats fed control diet $(\mathrm{O})$, galactomannan $(\boldsymbol{\square})$, arabinogalactan $(\boldsymbol{\Lambda})$ or glucomannan $(\times)$ were maintained in culture in media containing $\left[{ }^{14} \mathrm{C}\right]$ leucine $(185 \mathrm{kBq} / \mathrm{ml})$ for different time intervals. Medium was collected and analysed for $\left[{ }^{14} \mathrm{C}\right] \mathrm{apoB}$ by immunoprecipitation. For details of procedures, see p. 1023. Values are means with standard deviations depicted by vertical bars $(n 6)$. All mean values were significantly different from each other except between galactomannan and glucomannan: $P<0.05$. 
of $\left[{ }^{14} \mathrm{C}\right]$ leucine into the total TCA-precipitable protein secreted into the medium or that associated with the cell layer was not significantly different (data not shown), indicating that the decrease in $\left[{ }^{14} \mathrm{C}\right] \mathrm{apoB}$ was not a non-specific effect.

The cell layer-associated apoB radioactivity was also found to be decreased in cells derived from livers of rats fed galactomannan $(P<0.05)$, arabinogalactan $(P<0.05)$ and glucomannan $(P<0.05)$ compared to control rats (data not shown).

\section{Lipids associated with secreted lipoproteins}

A significant decrease in incorporation of $\left[{ }^{14} \mathrm{C}\right]$ acetate into lipids associated with secreted lipoprotein was observed in hepatocytes of rats fed galactomannan $(P<0.05)$, arabinogalactan $(P<0.05)$ and glucomannan $(P<0.05)$, when compared to control rats (Table 3$)$. Among the different lipids associated with lipoproteins that secreted into the medium, $\left[{ }^{14} \mathrm{C}\right]$ acetate incorporated into triacylglycerols, cholesterol and phospholipids were found to be decreased significantly in all the diet groups $(P<0 \cdot 05)$, when compared to control rats.

A significant decrease in the incorporation of $\left[{ }^{14} \mathrm{C}\right]$ acetate into total lipids and cholesterol associated with hepatocytes of rats fed mucilage diet, compared to control, was also observed. Among the different mucilage groups glucomannan and galactomannan showed more of an effect followed by arabinogalactan $(P<0 \cdot 05)$.

\section{Pulse chase analysis of apoB}

The rate of secretion of apoB-containing lipoproteins was studied by pulse labelling followed by chase analysis and the results are shown in Fig. 3. The $\left[{ }^{35} \mathrm{~S}\right]$ apoB radioactivity that secreted into the medium was quantitated. The rate of secretion of $\left[{ }^{35} \mathrm{~S}\right] \mathrm{apoB}$ was significantly low in hepatocytes from mucilage-fed rats. Among the mucilage-fed rats, the lowest rate of secretion was shown by hepatocytes from glucomannan-fed animals and this was in the order glucomannan $<$ galactomannan $<$ arabinogalactan $<$ control.

\section{Viscosity and water-holding capacity of mucilages}

In order to examine whether the hypolipidaemic effect of different mucilages is related to their physical characteristics, two important physical properties that may be physiologically relevant, namely viscosity and capacity to hold water, were determined and the results are given in Fig. 4. The relative viscosity of all the three mucilages increased with increase in concentration of the solution; $0.5 \%$ of the solution of the mucilages showed relative viscosity in the order galactomannan of fenugreek $>$ glucomannan of Dioscorea $>$ arabinogalactan of Colocasia. Similarly, the mucilages varied in their capacity to hold water and the water-holding capacity was in the order galactomannan $>$ glucomannan $>$ arabinogalactan.

\section{Discussion}

Comparison of the hypolipidaemic effect of mucilages isolated from fenugreek seeds, tubers of Colocasia esculenta and Dioscorea esculenta, which are chemically distinct, showed that the lipid-lowering effect involving decrease in the production of VLDL by the liver varied with the nature of the soluble fibre. The fenugreek seed mucilage is a galactomannan, the mucilages isolated from tubers of Colocasia and Dioscorea are arabinogalactan and glucomannan, respectively. Results presented earlier showed that the three mucilages, namely galactomannan, arabinogalactan and glucomannan, decrease lipid levels in both serum and tissues. Although serum total cholesterol was decreased significantly by galactomannan and glucomannan, all the mucilages increased the HDL/VLDL + LDL ratio and decreased serum triacylglycerols. Liver cholesterol, triacylglycerols and aortic triacylglycerols were decreased significantly by all the three mucilages, but significant decrease in aortic cholesterol was shown by galactomannan and glucomannan and not by arabinogalactan. Generally, dietary soluble or viscous fibres have hypocholesterolaemic effect (Anderson, 1990; Glore et al. 1994). For example soluble fibres such as phyllium, oat bran, guar and pectin decrease serum total cholesterol and LDL cholesterol without affecting serum triacylglycerols. The present results showed that the lipid-lowering effect varied with the nature of the mucilage and was in the order glucomannan $>$ galactomannan $>$ arabinogalactan. Mannanrich mucilage such as glucomannan showed more serum cholesterol- and triacylglycerol-lowering effect while the least effect was produced by mannan-free arabinogalactan. Although to a lesser extent, arabinogalactan also decreased serum lipids. But in a randomized controlled trial in normal

Table 3. Synthesis of VLDL by hepatocytes: incorporation of $\left[{ }^{14} \mathrm{C}\right]$ acetate into lipids $\left(\mathrm{dpm} / \mathrm{mg}\right.$ cell protein $\left.\times 10^{-3}\right)$ * (Mean values and standard deviations for six rats per group)

\begin{tabular}{|c|c|c|c|c|c|c|c|c|c|c|c|c|}
\hline & \multicolumn{8}{|c|}{ Medium } & \multicolumn{4}{|c|}{ Cell layer } \\
\hline & \multicolumn{2}{|c|}{ Total lipid } & \multicolumn{2}{|c|}{ Cholesterol } & \multicolumn{2}{|c|}{ Triacylglycerols } & \multicolumn{2}{|c|}{ Phospholipids } & \multicolumn{2}{|c|}{ Total lipids } & \multicolumn{2}{|c|}{ Cholesterol } \\
\hline & Mean & SD & Mean & SD & Mean & SD & Mean & SD & Mean & SD & Mean & SD \\
\hline Control & $174 \cdot 2^{d}$ & 1.01 & $24 \cdot 4^{b}$ & 1.52 & $98 \cdot 7^{d}$ & $2 \cdot 17$ & $39 \cdot 5^{c}$ & 1.97 & $1715 \cdot 4^{c}$ & $16 \cdot 66$ & $205 \cdot 8^{c}$ & 4.98 \\
\hline Galactomannan & $124 \cdot 2^{b}$ & 0.69 & $11.8^{\mathrm{a}}$ & 1.02 & $69 \cdot 0^{\mathrm{a}}$ & 1.34 & $26 \cdot 1^{\mathrm{b}}$ & 1.36 & $1265 \cdot 5^{a}$ & 24.53 & $162 \cdot 2^{\mathrm{a}}$ & 11.57 \\
\hline Arabinogalactan & $120 \cdot 8^{a}$ & 0.54 & $12 \cdot 2^{\mathrm{a}}$ & $1 \cdot 16$ & $72 \cdot 5^{b}$ & 0.90 & $26 \cdot 6^{b}$ & 1.01 & $1554 \cdot 2^{b}$ & 13.57 & $183 \cdot 6^{\mathrm{b}}$ & 13.58 \\
\hline Glucomannan & $130 \cdot 4^{c}$ & 0.83 & $10 \cdot 8^{a}$ & 0.90 & $84 \cdot 7^{\mathrm{c}}$ & 1.27 & $23.0^{\mathrm{a}}$ & 1.32 & $1285 \cdot 0^{a}$ & $10 \cdot 22$ & $156 \cdot 0^{a}$ & 11.48 \\
\hline
\end{tabular}

a,b,c,d Mean values within a column with unlike superscript letters were significantly different $(P<0.05)$.

${ }^{*}$ Hepatocytes were isolated from livers of rats of all groups and maintained in culture in the presence of $\left[{ }^{14} \mathrm{C}\right] \mathrm{acetate}(185 \mathrm{kBq} / \mathrm{ml})$ for $8 \mathrm{~h}$. Lipids associated with $\mathrm{VLDL}$ that secreted into the medium and that associated with cells were extracted and individual lipids were separated by TLC and radioactivity associated with each fraction was determined. For details of procedures, see p. 1023. 


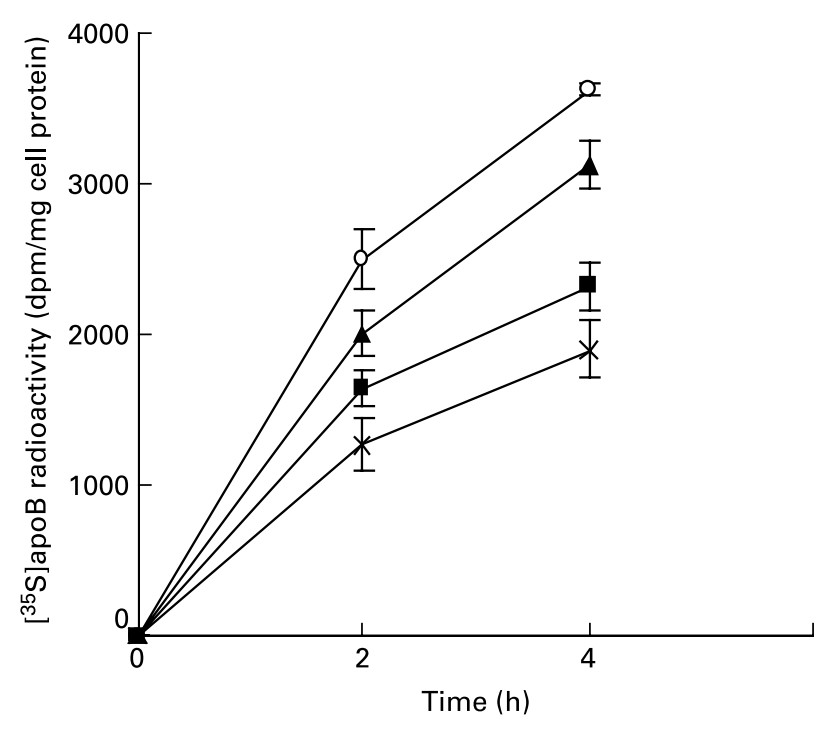

Fig. 3. Pulse chase analysis of the secretion of apoB-containing lipoproteins. Hepatocytes were isolated from livers of rats fed control diet $(O)$, galactomannan $(\mathbf{\square})$, arabinogalactan $(\mathbf{\Lambda})$ or glucomannan $(x)$ for 8 weeks. The isolated hepatocytes were maintained in culture in the presence of $\left[{ }^{35} \mathrm{~S}\right]$ methionine $(740 \mathrm{kBq} / \mathrm{ml})$ for $3 \mathrm{~h}$, removed from the medium, fresh nonradioactive medium was added and secretion into the medium of $\left[{ }^{35} \mathrm{~S}\right] \mathrm{apoB}$ was chased at different time intervals. For details of procedures, see p. 1023. Values are means with standard deviations depicted by vertical bars $(n 6)$. All mean values were significantly different from each other: $P<0.05$.

human subjects, intake of arabinogalactan did not produce any significant effect on serum lipids (Marett \& Slavin, 2004). Comparison of the effects of three different galactomannans of varying galactose content reported previously (Evans et al. 1992) showed that fenugreek galactomannan with a galactose to mannose ratio of 1:1 had a more cholesterol-lowering effect when compared to locust-bean gum galactomannan which contained a lower amount of galactose. But the level of galactomannan intake in the present study was much less. Further, the experimental animals were normocholesterolaemic. However, studies using cholesterol-fed animals also showed that galactomannan produced a significant hypocholesterolaemic effect (data not shown). Analysis of serum GOT, GPT, total protein and albumin:globulin ratio did not show any

\section{(A)}

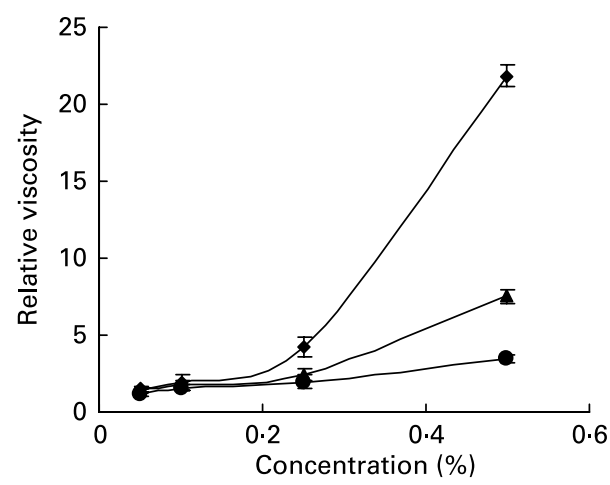

significant difference among control and mucilage-fed animals, indicating that the liver function of these animals has not been affected.

Different mechanisms have been suggested to explain the hypolipidaemic action of dietary fibres which include the decreased reabsorption of bile acids, interfering with lipid metabolism by SCFA produced in the colon by microbial fermentation. Results presented earlier indicate that the mucilages reduce VLDL and LDL lipids and apoB associated with these plasma lipoproteins. The synthesis and secretion of apoB by hepatocytes from livers of mucilage-fed animals was found to be decreased significantly by these three mucilages, indicating a decreased synthesis and secretion of VLDL particles. Decrease in $\left[{ }^{14} \mathrm{C}\right]$ acetate incorporation into total lipids and triacylglycerols associated with lipoproteins secreted into the medium also suggest a decreased production of VLDL by liver cells. This was further confirmed by pulse chase analysis which showed a decrease in the rate of secretion of apoB by hepatocytes from livers of mucilage-fed rats. Of the different mucilages, glucomannan produced the greatest decrease in the rate of production of VLDL and arabinogalactan produced the least. Liver is the major site for the synthesis of VLDL and the rate of production of VLDL by primary cultures of hepatocytes is a reflection of the nutritional status of the animal with respect to hepatic production of VLDL. Our previous studies showed that during early stages in culture, primary cultures of rat hepatocytes produce VLDL as the principal apoB-containing lipoprotein (Kumar et al. 1994). The present results thus indicate that glucomannan reduced the synthesis and secretion of VLDL by hepatocytes. Assembly and secretion of VLDL by hepatocytes is a complex process involving the synthesis of apoB, synthesis of lipids, their assembly and secretion. Availability of lipids, particularly endogenously produced triacylglycerols and nacently formed cholesterol/ester, is a critical factor in the assembly and secretion of VLDL (Davis, 1999; Olofsson et al. 1999). Although it is not clear how glucomannan and other non-digestible mucilages produce effects in liver, it is possible that the fermented products of these mucilages, primarily the SCFA, may affect hepatic synthesis of VLDL. The present in vitro studies using isolated hepatocytes in culture showed that butyrate and propionate reduced synthesis and secretion of apoB as VLDL (data not shown). The fermentation of dietary fibre in the

(B)

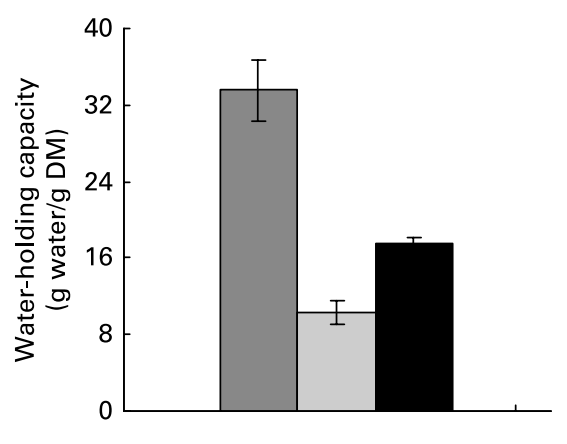

Fig. 4. Relative viscosity (A) and water-holding capacity (B) of mucilages. (A), Aqueous solutions of different mucilages ( $\bullet$, galactomannan; $\bullet$, arabinogalactan; $\boldsymbol{\Lambda}$, glucomannan) of varying concentrations were prepared and their relative viscosity with respect to water was determined using an Ostwald's viscometer. (B), Each mucilage ( $0.5 \mathrm{~g} ; \square$, galactomannan; $\square$, arabinogalactan; $\mathbf{\square}$, glucomannan) was suspended in water for $16 \mathrm{~h}$ and the amount of water held was determined. For details of procedures, see p. 1022. Values are means of triplicate experiments with standard deviations depicted by vertical bars. 
intestine by intestinal microflora produces SCFA. Although we have not analysed the nature of the fermentation products in our experiments, Pylkas et al. (2005) compared SCFA production by different dietary fibres using an in vitro fermentation model and found that SCFA production varied among the fibre from different sources. Hara et al. (1999) reported that SCFA suppress cholesterol synthesis in rat liver and intestine. Butyrate has been shown to impair lipid transport by inhibiting microsomal triacylglycerol transfer protein in Caco-2 cells and a reduction in triacylglycerol-rich lipoprotein output (Marcil et al. 2003). The present results of the incorporation studies showed a decrease in the synthesis of total lipids and cholesterol associated with hepatocytes from mucilage-fed rats. Thus decrease in production of VLDL by liver is clearly one of the mechanisms by which these mucilages lower lipid levels in serum and tissues.

An increase in the excretion of cholesterol and bile acids through faeces may be another reason for the hypolipidaemic effect of dietary fibres. It has been reported that feeding psyllium increased faecal bile acid and sterol excretion in rats (Buhman et al. 1998). De Schrijver et al. (1992) reported that with oat bran intake, there was an inverse linear relationship between plasma cholesterol concentration and faecal excretion of bile acids. The present results showed that there was significant increase in neutral sterol and bile acids excretion in rats fed these different mucilages but there was no difference in the amount of bile acids and neutral sterols excreted by animals receiving the different mucilages. Thus increase in excretion of neutral sterols and bile acids may be another reason for the hypolipidaemic effect of these mucilages, however, this may not explain the variation in the extent of lipid lowering shown by different mucilages.

It has been suggested that the hypocholesterolaemic effect of soluble fibres relates to their gel-forming properties (Anderson, 1995). Soluble fibres like gum acacia, which does not form a viscous solution in water, appear to have minimal hypolipidaemic effects (Haskell et al. 1992). Guar gum showed a significant cholesterol-lowering effect whereas hydrolysed guar gum did not show any significant cholesterol-lowering effect in man (Anderson et al. 1993). Viscosity and water-holding capacity of the mucilage depends on their structure and chemical composition. The present data indicate that galactomannan and glucomannan have relatively higher viscosity and water-holding capacity than arabinogalactan. Although there is no direct relation between the hypolipidaemic effect and the viscosity and water-holding capacity of the different mucilages tested here, it appears that the hypocholesterolaemic effect of these soluble fibres is related to their viscosity and water-holding capacity particularly because arabinogalactan, which showed the minimum viscosity and water-holding capacity, unlike other mucilages had the minimum plasma lipid-lowering effect. Similar studies from other laboratories have suggested that a moderate increase in viscosity of intestinal content is effective in reducing plasma cholesterol (Schneeman, 1999).

These gel-forming fibres have been suggested to contribute to hypolipidaemic action by decreasing the absorption of cholesterol or fatty acids and decreasing reabsorption of biliary cholesterol and bile acids in the gastrointestinal tract. As these fibres are free from any bioactive substances such as saponins, tocotrienols or carotenoids, it is unlikely that the hypocholesterolaemic effect is produced by any non-polysaccharide materials.
In conclusion, mucilages isolated from different sources differ in their physical and chemical nature. These mucilages differ in their potential to lower lipid levels in rats. A greater lipid-lowering effect was shown by mannans like glucomannan and galactomannan than arabinogalactan. The hypolipidaemic effect of these mucilages appears to be due to a decrease in the synthesis and secretion of VLDL by hepatocytes. A decrease in production of VLDL can be due to a decrease in the synthesis of apoB as well as lipids associated with VLDL. Differences in the gelling property and viscosity which depend on the chemical nature of the mucilage may affect cholesterol and fatty acid absorption from the intestine and reduction in the availability of lipids can affect the assembly and secretion of VLDL by liver cells. Further, fermentation products like butyrate and propionate decrease VLDL production by liver cells. Thus the present results suggest that differences in the chemical nature of these mucilages contribute significantly to the differences in their physiological effects.

The present results are also relevant in human nutrition and health, particularly because mannan-rich soluble fibres are more effective in reducing lipid levels. There are a number of plant-based food materials rich in mannan-containing soluble fibres. The materials selected in the present study as sources of soluble fibres, such as fenugreek and tubers, form part of the diet for different populations. For example, fenugreek is used as a spice whereas Dioscorea is used as a vegetable. As elevated blood lipids are one of the major risk factors in the development of chronic conditions like atherosclerosis, diet-based lipid lowering is a useful approach. Further controlled studies on hypercholesterolaemic human subjects are required to establish whether such fibres can promote reverse cholesterol transport and regression of atheromatous lesions.

\section{Acknowledgement}

P. T. Boban was supported by a research fellowship from the Council of Scientific and Industrial Research, New Delhi.

\section{References}

Anderson JW (1985) Physiological and metabolic effects of dietary fiber. Fed Proc 44, 2902-2906.

Anderson JW (1990) Dietary fiber and human health. Hortic Sci 25, $1488-1495$.

Anderson JW (1995) Cholesterol lowering effect of soluble fiber in humans. In Dietary Fiber in Health and Disease, pp. 126-145 [D Kritchevsky and C Bonfield, editors]. St Paul, MN: Eagan Press.

Anderson JW \& Hanna TJ (1999) Impact of nondigestible carbohydrates on serum lipoproteins and risk for cardiovascular disease. J Nutr 129, 1457S-1466S.

Anderson JW, Jones AE \& Riddell-Mason S (1994) Ten different dietary fibers have significantly different effects on serum and liver lipids of cholesterol-fed rats. J Nutr 124, 78-83.

Anderson SA, Fischer KD \& Talbott JM (1993) Evaluation of the Health Aspects of Using Particularly Hydrolysed Guar Gum as a Food Ingredient. Bethesda, MD: Life Science Research Office, Federation of American Societies for Experimental Biology.

Anil K, Abraham R, Kumar GS, Sudhakaran PR \& Kurup PA (1992) Metabolism of very low density lipoproteins - effect of sardine oil. Indian J Exp Biol 30, 518-522.

Anil K \& Sudhakaran PR (1994) Blocking of alcohol induced effects on synthesis and secretion of apoB containing lipoproteins by 
substituting sardine oil in the diet. Indian J Biochem Biophys 32, $44-48$.

Buhman KK, Furumoto EJ, Donkin SS \& Story JA (1998) Dietary psyllium increases fecal bile acid excretion, total steroid excretion and bile acid biosynthesis in rats. J Nutr 128, 1199-1203.

Carr JJ \& Drektor IJ (1956) Simplified rapid technique for the extraction and determination of serum cholesterol without saponification. Clin Chem 2, 353-368.

Carr TP, Gallaher DD, Yang CH \& Hassel CA (1996) Increased intestinal contents viscosity reduces cholesterol absorption efficiency in hamsters fed hydroxypropyl methylcellulose. J Nutr 126, $1463-1469$.

Chen WJ, Anderson JW \& Jennings D (1984) Propionate may mediate the hypocholesterolemic effects of certain soluble plant fibers in cholesterol-fed rats. Proc Soc Exp Biol Med 175, 215-218.

Davis RA (1999) Cell and molecular biology of the assembly and secretion of apolipoproteinB-containing lipoproteins by the liver. Biochim Biophys Acta 1440, 1-31.

De Schrijver R, Fremaut D \& Verheyen A (1992) Cholesterol-lowering effects and utilization of protein, lipid, fiber and energy in rats fed unprocessed and baked oat bran. J Nutr 122, 1318-1324.

Evans AJ, Hood RL, Oakenfull DG \& Sidhu GS (1992) Relationship between structure and function of dietary fibre: a comparative study of the effects of three galactomannans on cholesterol metabolism in the rat. Br J Nutr 68, 217-229.

Folch J, Lees M \& Sloane-Stanley GH (1957) A simple method for isolation and purification of total lipids from animal tissue. $J$ Biol Chem 226, 497-509.

Fossati P \& Prencipe L (1982) Serum triglycerides determined calorimetrically with an enzyme that produces hydrogen peroxide. Clin Chem 28, 2077-2080.

Gallaher DD, Hassel CA, Lee KJ \& Gallaher CM (1993) Viscosity and fermentability as attributes of dietary fiber responsible for the hypocholesterolemic effect in hamsters. $J$ Nutr 123, $244-252$.

Gidez LI, Miller GJ, Burstein M, Slagle S \& Eder HA (1982) Separation and quantitation of subclasses of human plasma high density lipoproteins by a simple precipitation procedure. J Lipid Res $\mathbf{2 3}$, $1206-1223$.

Glore SR, Van Treeck DV, Knehaus AW \& Guild M (1994) Soluble fiber and serum lipids: a literature review. J Am Diet Assoc 94, 425-436.

Grundy SM, Ahrens EH \& Miettinen TA (1965) Quantitative isolation and GLC analysis of total fecal bile acids. J Lipid Res 6 , $397-410$

Hara H, Haga S, Aoyama Y \& Kiriyama S (1999) Short-chain fatty acids suppress cholesterol synthesis in rat liver and intestine. J Nutr 129, 942-948.

Haskell WL, Spiller GA, Jensen CD, Ellis BK \& Gates JE (1992) Role of water-soluble dietary fiber in the management of elevated plasma cholesterol in healthy human subjects. Am J Cardiol 69, 433-439.

Kay RM (1982) Dietary fiber. J Lipid Res 23, 221-242.

Kochert G (1978) Carbohydrate determination by phenol-sulphuric acid method. In Handbook of Phycological Methods: Physiological and Biochemical Methods, pp. 95-97 [JA Hellebust and JS Craigie, editors]. Cambridge: Cambridge University Press.

Kritchevsky D \& Stony JA (1986) Influence of dietary fiber on cholesterol metabolism in experimental animals. In Dietary Fiber in Human Nutrition: CRC Handbook of Boca Raton, pp. 129-142 [GA Spiller, editor]. Boca Raton, FL: CRC Press.

Kumar NS, Abraham R, Kumar GS, Sudhakaran PR \& Kurup PA (1994) Synthesis and secretion of lipoproteins by primary cultures of rat hepatocytes. Indian J Biochem Biophys 31, 62-67.

Laemmli UK (1970) Cleavage of structural proteins during the assembly of the head of bacteriophage T4. Nature 227, 680-685.

Lowry OH, Rosebrough NJ, Farr AL \& Randall RJ (1951) Protein measurement with the folin phenol reagent. J Biol Chem 193, $265-275$.

Marcil V, Delvin E, Grovel C \& Levy E (2003) Butyrate impairs lipid transport by inhibiting microsomal triglyceride transfer protein in Caco-2 cells. J Nutr 133, 2180-2183.

Marett R \& Slavin JL (2004) No long-term benefits of supplementation with arabinogalactan on serum lipids and glucose. $J \mathrm{Am}$ Diet Assoc 104, 636-639.

McConnell AA, Eastwood MA \& Mitchell WD (1974) Physical characteristics of vegetable food stuffs that could influence bowel function. J Sci Food Agric 25, 1457-1464.

Menon PV \& Kurup PA (1976) Effect of fiber rich polysaccharide from blackgram on cholesterol metabolism in rats fed normal and atherogenic diet. Biomedicine 24, 248-253.

Olofsson SO, Asp L \& Boren J (1999) The assembly and secretion of apolipoproteinB-containing lipoproteins. Curr Opin Lipidol 10, $341-346$

Pylkas AM, Juneja LR \& Slavin JL (2005) Comparison of different fibers for in vitro production of short chain fatty acids by intestinal microflora. J Med Food 8, 113-116.

Reitman S \& Frankel S (1957) A colorimetric method for the determination of serum glutamate oxaloacetate and glutamate pyruvate transaminases. Am J Clin Pathol 28, 56-63.

Schneeman BO (1999) Building scientific consensus: the importance of dietary fiber. Am J Clin Nutr 45, 129-132.

Schneeman BO \& Tietyen J (1994) Dietary fiber. In Modern Nutrition in Health and Disease, 8th ed., pp. 89-100 [ME Shills, JA Olson and M Shike, editors]. Philadelphia, PA: Lea and Febiger.

Seglen PO (1976) Preparation of isolated liver cells. In Methods in Cell Biology, 13th ed., pp. 30-78 [DM Prescott, editor]. New York: Academic Press.

Skipski VP, Good JJ, Barclay M \& Reggio RB (1968) Quantitative analysis of simple lipid classes by thin-layer chromatography. Biochim Biophys Acta 152, 10-19.

Sudhakaran PR, Sinn W \& von Figura K (1980) Regulation of heparin sulfate metabolism by adenosine $3^{\prime} 5^{\prime}$ cyclic monophosphate in hepatocytes in culture. Biochem $J$ 192, 395-401.

Van Handel E \& Zilversmith DB (1957) Micromethod for the direct determination of serum triglycerides. J Lab Clin Med 50, 152-157.

Van Horn L (1997) Fiber, lipids, and coronary heart disease. Circulation 95, 2701-2704.

Zlatkis A, Zak B \& Boyle AJ (1953) A new method for the direct determination of serum cholesterol. J Lab Clin Med 41, 486-492. 